Journal of Mathematics and Statistics 2 (4): 464-468, 2006

ISSN 1549-3644

(C) 2006 Science Publications

\title{
Regionalization Method for Nonlinear Differential Equation Systems In a Cartesian Plan
}

\author{
Belaib Lekhmissi \\ Department of Mathematics \\ Faculty of Sciences, University of Oran Es-Senia, Algeria
}

\begin{abstract}
We propose a regionalization technique for analyzing nonlinear differential equation systems where coefficients are standard and nonzero. The present work starts with the study of a natural object which was the magic squares providing us with a new way to partition the plan in regions.
\end{abstract}

Key words: Internal Set Theory, Regionalization, nonlinear differential equations, operator

\section{INTRODUCTION}

In the present work we study the effects of delinearity of box type in orbital geometry and in orbital dynamics. We start this work with a first natural object around which we organize our plan, namely the magic square (MS) giving the partition of the plan $\mathfrak{R}^{2}$ into 25 external sets depicted in the following heuristic diagram .

\begin{tabular}{crrrr}
\hline 15 & 22 & 9 & 16 & 3 \\
2 & 14 & 21 & 8 & 20 \\
19 & 1 & 13 & 25 & 7 \\
6 & 18 & 5 & 12 & 24 \\
23 & 10 & 17 & 4 & 11 \\
\hline
\end{tabular}

Also, it plays an essential role in the nonclassic partition (regionalization) as following $\left(\Re, G_{-} \cup A \cup P \cup A_{+} \cup G_{+}\right.$) of $\mathfrak{R}$.

Here are some of the questions that can be asked

The apparition of the magic square

The behaviour of the orbits in the regions of the MS

The transition of the orbits of a region have the other

The nature of the singular place

The strut with the linear case.

The objects: We are interested by non-standard systems of nonlinear differential equations in $\mathfrak{R}^{2}$ provided with cartesian coordinates $\left(\mathrm{X}_{1}, \mathrm{X}_{2}\right)$.

$$
\left\{\begin{array}{l}
X_{1}^{\prime}=a_{11} X_{1}^{\left[\alpha_{1}\right]}+a_{12} X_{2}^{\left[\alpha_{2}\right]}+b_{1} \\
X_{2}^{\prime}=a_{21} X_{1}^{\left[\alpha_{1}\right]}+a_{22} X_{2}^{\left[\alpha_{2}\right]}+b_{2}
\end{array}\right.
$$

where the reals $a_{11}, a_{12}, a_{21}, a_{22}, b_{1}, b_{2}\left(\operatorname{resp} \alpha_{1}>0, \alpha_{2}>0\right)$ are standard and nonzero (resp infinitely great)

$$
\text { and for } \mathrm{i}=1,2\left\{\begin{array}{lll}
X_{i}^{\left[\alpha_{i}\right]}=X_{i}^{\alpha_{i}} & \text { if } \quad X_{i} \geq 0 \\
X_{i}^{\left[\alpha_{i}\right]}=\left(-X_{i}\right)^{\alpha_{i}} & \text { if } \quad X_{i} \prec 0
\end{array}\right.
$$

we proceed to a sharp delinearization " of box type delinearization " of differential system with constant coefficients

$\left\{\begin{array}{l}X_{1}^{\prime}=a_{11} X_{1}+a_{12} X_{2}+b_{1} \\ X_{2}^{\prime}=a_{21} X_{1}+a_{22} X_{2}+b_{2}\end{array}\right.$

With conserving the linear equations.

Then the problem is to evaluat the effects.

We can also see a problem of transient to the limit $\left(\alpha_{1} \rightarrow+\infty \quad, \alpha_{2} \rightarrow+\infty\right)$

In some families which are linear when $\alpha_{1}=\alpha_{2}=1$.

The differential system (1) is divided into three families : $F_{1}, F_{2}, F_{3}$

$\mathrm{F}_{1}:\left(\mathrm{a}_{21}, \mathrm{a}_{22}, \mathrm{~b}_{2}\right)=\mathrm{m}\left(\mathrm{a}_{11}, \mathrm{a}_{12}, \mathrm{~b}_{1}\right)$

$\mathrm{F}_{2}:\left(\mathrm{a}_{21}, \mathrm{a}_{22}, \mathrm{~b}_{2}\right)=\mathrm{m}\left(\mathrm{a}_{11}, \mathrm{a}_{12}, \mathrm{~b}_{1}\right)+(0,0, \mathrm{~d}) ; \mathrm{d} \neq 0$

$\mathrm{F}_{3}$ : $\operatorname{rang}\left(\begin{array}{ll}a_{11} & a_{12} \\ a_{21} & a_{22}\end{array}\right)=2$

The technique: we use the technique of regionalization to get some predictions relative to the macroscopic behaviour of orbits and the dynamics along the orbits.

Some predictions

i. The magic square (MS) in the first analysis the plan $\mathfrak{R}^{2}$ is partitioned in 25 external regions where we denote by

(15) (resp (3)) the region defined by the conditions $X_{1} \prec \prec-1$ and $X_{2} \succ \succ 1$ (resp $X_{1} \succ \succ 1$ and $X_{2}$ $\succ \succ 1)$

(22) (resp (16)) the region defined by the conditions

Corresponding Author: $\quad$ Belaib Lekhmissi, Département de Mathématiques, Faculté des Sciences Université D’Oran 
$X_{1} \approx-1$ and $X_{2} \succ \succ 1\left(\operatorname{resp} X_{1} \approx 1\right.$ and $\left.X_{2} \succ \succ 1\right)$ (9) (resp (17)) the region defined by the conditions

$X_{1} \quad \prec \prec 1$ and $X_{2} \quad \succ \succ 1$ (resp $\left|X_{1}\right| \prec \prec 1$ and

$\left.X_{2} \prec \prec-1\right)$

(2) (resp (20)) the region defined by the conditions

$X_{1} \prec \prec-1$ and $X_{2} \approx 1$ (resp $X_{1} \succ \succ 1$ and $X_{2} \approx 1$ )

(14) (resp (8)) the region defined by the conditions

$X_{1} \approx-1$ and $X_{2} \approx 1\left(\operatorname{resp} X_{1} \approx 1\right.$ and $\left.X_{2} \approx 1\right)$

(21) (resp (5)) the region defined by the conditions

$\left|X_{1}\right| \prec \prec 1$ and $X_{2} \approx 1$ (resp $\left|X_{2}\right| \prec \prec 1$ and $X_{2}$

$\approx-1)$

(19) (resp (7)) the region defined by the conditions

$X_{1} \prec \prec-1$ and $\left|X_{2}\right| \prec \prec 1 \quad$ (resp $X_{1} \succ \succ 1$ and

$\left.\left|X_{2}\right| \prec \prec 1\right)$

(1) (resp (25)) the region defined by the conditions

$X_{1} \approx-1$ and $\left|X_{2}\right| \prec \prec 1 \quad$ (resp $X_{1} \approx 1$ and $\left.\left|X_{2}\right| \prec \prec 1\right)$

(1) (resp (25)) the region defined by the conditions

$X_{1} \prec \prec-1$ and $\left|X_{2}\right| \prec \prec 1 \quad$ (resp $X_{1} \approx 1$ and $\left.\left|X_{2}\right| \prec \prec 1\right)$

(13) the region defined by the conditions

$\left|X_{1}\right| \prec \prec 1$ and $\left|X_{2}\right| \prec \prec 1$

(6) (resp (24)) the region defined by the conditions

$X_{1} \prec \prec-1$ and $X_{2} \approx-1$ (resp $X_{1} \succ \succ 1$ and

$\left.X_{2} \approx-1\right)$

(18) (resp (12)) the region defined by the conditions

$X_{1} \approx-1$ and $X_{2} \approx-1\left(\operatorname{resp} X_{1} \approx 1\right.$ and $\left.X_{2} \approx-1\right)$

In (13) the macroscopic behaviour is determined by the rectiligne system

$\left\{\begin{array}{l}X_{1}^{\prime} \approx b_{1} \\ X_{2}^{\prime} \approx b_{2}\end{array}\right.$

In (9) (resp (17)) the macroscopic behaviour is determined by rectiligne system

$\left\{\begin{array}{l}X_{1}^{\prime} \approx a_{12} \\ X_{2}^{\prime} \approx a_{22}\end{array}\right.$

in (19)(resp (7)) the macroscopic behaviour is determined by the rectiligne system

$\left\{\begin{array}{l}X_{1}^{\prime} \approx a_{11} \\ X_{2}^{\prime} \approx a_{21}\end{array}\right.$

The refined magic square: to know the orbit behaviour in the other regions

$(15,22,16,3,2,14,21,8,20,1,25,6,18,12,24,23,10,4,11)$
We must refine the magic square (MS) by introducing the extensions $13^{\prime}, 9^{\prime}, 17^{\prime}, 7^{\prime}, 19^{\prime}$ of the regions $13,9,17,7,19$ respectively by the following conditions 13': $a_{11} X_{1}^{\left[\alpha_{1}\right]}+a_{12} X_{2}^{\left[\alpha_{2}\right]} \in P$ and $a_{21} X_{1}^{\left[\alpha_{1}\right]}+a_{22} X_{2}^{\left[\alpha_{2}\right]} \in P$ $9^{\prime}: X_{2}^{\left[\alpha_{2}\right]} \in G_{+}$and $\frac{X_{1}^{\left[\alpha_{1}\right]}}{X_{2}^{\left[\alpha_{2}\right]} \in P}$ $1^{\prime}: X_{2}^{\left[\alpha_{2}\right]} \in G_{-}$and $\frac{X_{1}^{\left[\alpha_{1}\right]}}{X_{2}^{\left[\alpha_{2}\right]}} \in P$ $7^{\prime}: X_{1}^{\left[\alpha_{1}\right]} \in G_{+}$and $\frac{X_{2}^{\left[\alpha_{2}\right]}}{X_{1}^{\left[\alpha_{1}\right]}} \in P$

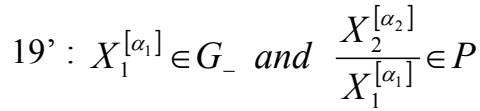

The family $\mathbf{F}_{1}$ : the function $F=X_{2}-m X_{1}$ is a first integral.

The non-singular orbits are rectiligne and with the same slope $\mathrm{m}$, the singular position is given by the equation

$a_{11} X_{1}^{\left[\alpha_{1}\right]}+a_{12} X_{2}^{\left[\alpha_{2}\right]}+b_{1}=0$

with the prime integral $F=X_{2}-m X_{1}$ a differential system of the family F1 induce a family with one real parameter $\mathrm{C}$ (C specify the level straight) of differential equation of order 1 in $\mathfrak{R}$.

Namely, $D_{C}: \quad a_{11} X_{1}^{\left[\alpha_{1}\right]}+a_{12}\left(m X_{1}+C\right)^{\left[\alpha_{2}\right]}+b_{1}$

the form of singular place of $F_{1}$ implique some number of bifurcations in the equations $D_{c}$ when $C$ follow $\mathfrak{R}$.

\section{The family $\mathbf{F}_{2}$}

$F_{2}\left\{\begin{array}{l}X_{1}^{\prime}=a_{11} X_{1}^{\left[\alpha_{1}\right]}+a_{12} X_{2}^{\left[\alpha_{2}\right]}+b_{1} \\ X_{2}^{\prime}=m\left(a_{11} X_{1}^{\left[\alpha_{1}\right]}+a_{12} X_{2}^{\left[\alpha_{2}\right]}+b_{1}\right)+d, d \neq 0\end{array}\right.$

The singular place is empty

If $\mathrm{d}$ was null we obtain a system of $F_{1}$ with a singular emptiness in the case to add $d \neq 0$ hunts the singular place, but it stay a witness that create a river phenomena.

\section{The family $F_{3}$ :}

we distinguish three cases

j. the vectors $\left(a_{11}, a_{21}\right),\left(b_{1}, b_{2}\right),\left(a_{12}, a_{22}\right)$ are pairwise independent.

jj. $\left|\begin{array}{ll}a_{11} & b_{1} \\ a_{21} & b_{2}\end{array}\right| \neq 0 \quad ;\left|\begin{array}{ll}a_{12} & b_{1} \\ a_{22} & b_{2}\end{array}\right| \neq 0$

Proposition 1: In region (13) of magic square (MS) the macroscopic behaviour of orbits is determined by the rectiligne system 
$\left\{\begin{array}{l}X_{1}^{\prime} \approx b_{1} \\ X_{2}^{\prime} \approx b_{2}\end{array}\right.$

Let $D=\frac{\partial}{\partial_{i}}$ denote the derivation operator as regard $X_{i}$ and state the following result :

Lemma 1: In the region (13) of the magic square (MS) the field of vectors

$$
Y=\left(a_{11} X^{\left\lceil a_{1}\right]}+a_{12} X^{\left\{\alpha_{2}\right]}+b\right) D+\left(a_{2} X^{\left.X \alpha_{1}\right]}+a_{22} X^{\left\lceil\alpha_{2}\right]}+b_{2}\right) D_{2}
$$

(associated to the system (1)) is infinitely near to the rectiligne field vectors $Y_{13}=b_{1} D_{1}+b_{2} D_{2}$

Proof of lemma 1: consider the region (13) defined by the conditions

$$
\left|X_{1}\right| \prec \prec 1 \text { and }\left|X_{2}\right| \prec \prec 1
$$

Or the field vectors:

$Y=\left(a_{11} X^{\left[\alpha_{1}\right]}+a_{12} X^{\left[\alpha_{2}\right]}+b_{1}\right) D_{1}+\left(a_{21} X^{\left[\alpha_{1}\right]}+a_{22} X^{\left[\alpha_{2}\right]}+b_{2}\right) D_{2}$

Associated to the system

$$
\left\{\begin{array}{l}
X_{1}^{\prime}=a_{11} X_{1}^{\left[\alpha_{1}\right]}+a_{12} X_{2}^{\left[\alpha_{2}\right]}+b_{1} \\
X_{2}^{\prime}=a_{21} X_{1}^{\left[\alpha_{1}\right]}+a_{22} X_{2}^{\left[\alpha_{2}\right]}+b_{2}
\end{array}\right.
$$

as $\left|X_{1}\right| \prec \prec 1$ and $\left|X_{2}\right| \prec \prec 1$ and $\alpha_{1} \succ 0, \alpha_{2} \succ 0$ are real infinitude great

$X_{1}^{\left[\alpha_{1}\right]}$ and $X_{2}^{\left[\alpha_{2}\right]}$ are infinitude small.

consequently the field of vector $\mathrm{Y}$ in the coordinates $\left(X_{1}, X_{2}\right)$ is infinitely near to the rectligne field $Y_{13}=b_{1} D_{1}+b_{2} D_{2}$

Proof of proposition 1: By the lemma of short shadows, the orbits of (1) have in the region (13) the same halo as the system orbits

$$
\left\{\begin{array}{l}
X_{1}^{\prime} \approx b_{1} \\
X_{2}^{\prime} \approx=b_{2}
\end{array}\right.
$$

Proposition 2: In the regions (19) and (7) (resp (9) and (17) ) of the magic square MS the macroscopic of the orbits behaviour has infinitely small fluctuations near is determined by the rectligne system

$$
\left\{\begin{array} { l } 
{ X _ { 1 } ^ { \prime } \approx a _ { 1 1 } } \\
{ X _ { 2 } ^ { \prime } \approx a _ { 2 1 } }
\end{array} \quad \left(\operatorname{resp} \quad\left\{\begin{array}{l}
X_{1}^{\prime} \approx a_{12} \\
X_{2}^{\prime} \approx a_{22}
\end{array}\right)\right.\right.
$$

Lemma 2: In the regions (19) and (17) (resp 19' and $\left.\left(17^{\prime}\right)\right)$ of the magic square (MS) the field of vectors

$Y=\left(a_{11} X_{1}^{\left[\alpha_{1}\right]}+a_{12} X_{2}^{\left[\alpha_{2}\right]}+b_{1}\right) D_{1}+\left(a_{21} X_{1}^{\left[\alpha_{1}\right]}+a_{22} X_{2}^{\left[\alpha_{2}\right]}+b_{2}\right) D_{2}$ Associated to the system (1) is infinitely near of the rectiligne field of vectors

$$
\begin{aligned}
& Y_{1}=\left(a_{11}+\frac{a_{12} X_{2}^{\left[\alpha_{2}\right]}+b_{1}}{X_{1}^{\left[\alpha_{1}\right]}}\right) D_{1}+\left(a_{21}+\frac{a_{22} X_{2}^{\left[\alpha_{2}\right]}+b_{2}}{X_{1}^{\left[\alpha_{1}\right]}}\right) D_{2} \\
& \left(\operatorname{resp} Y_{2}=\left(a_{12}+\frac{a_{11} X_{1}^{\left[\alpha_{2}\right]}+b_{1}}{X_{2}^{\left[\alpha_{2}\right]}}\right) D_{1}+\left(a_{22}+\frac{a_{21} X_{2}^{\left[\alpha_{2}\right]}+b_{2}}{X_{2}^{\left[\alpha_{2}\right]}}\right) D_{2}\right)
\end{aligned}
$$

and $Y_{1}\left(\operatorname{resp} Y_{2}\right)$ is infinitely near of the rectiligne field of vectors

$$
Y_{1}=a_{11} D_{1}+a_{21} D_{2} \quad\left(\operatorname{resp} Y_{2}=a_{12} D_{1}+a_{22} D_{2}\right) \text {. }
$$

Proof of lemma 2: In the regions (19) and (17)(resp (9) and (17)) of the magic square MS $X_{2}^{\left[\alpha_{2}\right]}\left(\operatorname{resp} X_{1}^{\left[\alpha_{1}\right]}\right) \quad$ is infinitely small $X_{1}^{\left[\alpha_{1}\right]}\left(\operatorname{resp} X_{2}^{\left[\alpha_{2}\right]}\right)$ is infinitely great since $\alpha_{1} \succ 0, \alpha_{2} \succ 0$ are infinitely great Taking $X_{1}^{\left[\alpha_{1}\right]}$ (resp $\left.X_{2}^{\left[\alpha_{2}\right]}\right)$ as factor we can write the field of vectors :

$$
Y=\left(a_{11} X^{\left[\alpha_{1}\right]}+a_{12} X^{\left[\alpha_{2}\right]}+b_{1}\right) D_{1}+\left(a_{21} X^{\left[\alpha_{1}\right]}+a_{22} X^{\left[\alpha_{2}\right]}+b_{2}\right) D_{2}
$$

Under the form

$$
\begin{aligned}
& \left.Y_{1}=X_{1}^{\left[\alpha_{1}\right]}\left(a_{11}+\frac{a_{12} X_{2}^{\left[\alpha_{2}\right]}+b_{1}}{X_{1}^{\left[\alpha_{1}\right]}}\right) D_{1}+\left(a_{21}+\frac{a_{22} X_{2}^{\left[\alpha_{2}\right]}+b_{2}}{X_{2}^{\left[\alpha_{21}\right]}}\right)\right) D_{2} \\
& \left(\operatorname{resp} Y_{2}=X_{2}^{\left[\alpha_{2}\right]}\left(a_{12}+\frac{a_{11} X_{1}^{\left[\alpha_{2}\right]}+b_{1}}{X_{2}^{\left[\alpha_{1}\right]}}\right) D_{1}+\left(a_{22}+\frac{a_{21} X_{2}^{\left[\alpha_{2}\right]}+b_{2}}{X_{2}^{\left[\alpha_{21}\right]}}\right) D_{2}\right)
\end{aligned}
$$

In the regions (19) and (7) (resp (9) and (17)) of the magic square the field $Y$ has the same orbits as the field $Z_{1}=\left(a_{11}+\frac{a_{12} X_{2}^{\left[\alpha_{2}\right]}+b_{1}}{X_{1}^{\left[\alpha_{1}\right]}}\right) D_{1}+\left(a_{21}+\frac{a_{22} X_{2}^{\left[\alpha_{2}\right]}+b_{2}}{X_{1}^{\left[\alpha_{1}\right]}}\right) D_{2}$ $\left(\operatorname{resp} Z_{2}=\left(a_{12}+\frac{a_{11} X_{1}^{\left[\alpha_{2}\right]}+b_{1}}{X_{2}^{\left[\alpha_{2}\right]}}\right) D_{1}+\left(a_{22}+\frac{a_{21} X_{2}^{\left[\alpha_{2}\right]}+b_{2}}{X_{2}^{\left[\alpha_{2}\right]}}\right) D_{2}\right)$

The field $Z_{1}\left(\operatorname{resp} Z_{2}\right)$ is infinitely near of the rectiligne field

$Z_{1}^{\prime}=a_{11} D_{1}+a_{21} D_{2} \quad\left(\operatorname{resp} Z_{2}^{\prime}=a_{12} D_{1}+a_{22} D_{2}\right)$.

as the quantities

$$
\begin{aligned}
& \left(\frac{a_{12} X_{2}^{\left[\alpha_{2}\right]}+b_{1}}{X_{1}^{\left[\alpha_{1}\right]}}\right) \quad\left(\operatorname{resp}\left(\frac{a_{22} X_{2}^{\left[\alpha_{2}\right]}+b_{1}}{X_{2}^{\left[\alpha_{2}\right]}}\right)\right. \\
& \text { and }\left(\frac{a_{11} X_{1}^{\left[\alpha_{2}\right]}+b_{2}}{X_{1}^{\left[\alpha_{1}\right]}}\right)\left(\operatorname{resp}\left(\frac{a_{21} X_{1}^{\left[\alpha_{1}\right]}+b_{2}}{X_{2}^{\left[\alpha_{21}\right]}}\right)\right)
\end{aligned}
$$

are infinitely small.

Proof of proposition 2: The proposition 2 is an immediate consequence of the lemma of the short shadows as long as we have lemma 2.

Examination of the family F3:

$$
F_{3}: \operatorname{rang}\left(\begin{array}{ll}
a_{11} & a_{12} \\
a_{21} & a_{22}
\end{array}\right)=2
$$

We note

1. we can write 


$$
\begin{gathered}
\left(\begin{array}{l}
b_{1} \\
b_{2}
\end{array}\right)=\left(\begin{array}{l}
a_{11} \\
a_{21}
\end{array}\right) \alpha+\left(\begin{array}{l}
a_{12} \\
a_{22}
\end{array}\right) \beta ; \quad \alpha^{2}+\beta^{2} \succ 0 \\
\left\{\begin{array}{l}
X_{1}^{\prime}=a_{11}\left(X_{1}^{\left[\alpha_{1}\right]}+\alpha\right)+a_{12}\left(X_{2}^{\left[\alpha_{2}\right]}+\beta\right) \\
X_{2}^{\prime}=a_{21}\left(X_{1}^{\left[\alpha_{1}\right]}+\alpha\right)+a_{22}\left(X_{2}^{\left[\alpha_{2}\right]}+\beta\right)
\end{array}\right. \\
\alpha^{2}+\beta^{2} \succ 0
\end{gathered}
$$

2. the singular point is reduced to the point $\mathrm{S}=$ $\left((-\alpha)^{\left[\frac{1}{\alpha_{1}}\right]},(-\beta)^{\left[\frac{1}{\alpha_{2}}\right]}\right)$

3. the singular point can only be find in the halo of a corner the unit square.

4. the slow region is given by $X_{1}^{\left[\alpha_{1}\right]}+\alpha \approx 0, X_{2}^{\left[\alpha_{2}\right]}+\beta \approx 0$ other

$$
X_{1} \in(\operatorname{hal}(-\alpha))^{\left[\frac{1}{\alpha_{1}}\right]} \text { and } X_{1} \in(\operatorname{hal}(-\alpha))^{\left\lceil\frac{1}{\alpha_{2}}\right]}
$$

5. if $\alpha \beta \neq 0$, the slow region is strictly contained in the halo of $(\operatorname{sign}(-\alpha), \operatorname{sign}(-\beta))$.

if $\alpha=0 \neq \beta$, the slow region is given by $X_{1} \in P^{\left[\frac{1}{\alpha_{1}}\right]} \quad$ and $\quad X_{2} \approx(\operatorname{sign}(-\beta))^{\left[\frac{1}{\alpha_{2}}\right]}$. if $\alpha \neq 0=\beta$, the slow region is given by $X_{2} \in P^{\left[\frac{1}{\alpha_{2}}\right]} \quad$ and $\quad X_{1} \in(\operatorname{hal}(-\alpha))^{\left[\frac{1}{\alpha_{1}}\right]}$

6. the singular point is in the external square ES defined by $X_{1}{ }^{\left[\alpha_{1}\right]} \in L, X_{2}{ }^{\left[\alpha_{2}\right]} \in L$

Then in the region $X_{1}{ }^{\left[\alpha_{1}\right]_{e}} \in G, X_{2}{ }^{\left[\alpha_{2}\right]} \in G$, the curves $\mathrm{C}_{1}=\left(\mathrm{X}_{1}{ }_{1}=0\right)$ and $\mathrm{C}_{2}=\left(\mathrm{X}_{2}{ }_{2}=0\right)$

don't intersect.

\section{Proposition 3}

Given $(p, q)$ a singular point of the system (1)

i. $\quad$ if $|p| \prec \prec 1 \quad(\operatorname{resp}|q| \prec \prec 1)$ then:

* $|q| \approx 1(\operatorname{resp}|p| \approx 1)$

* $\frac{b_{1}}{b_{2}} \approx \frac{a_{12}}{a_{22}}\left(\operatorname{resp} \frac{b_{1}}{b_{2}} \approx \frac{a_{11}}{a_{21}}\right)$

ii. if $0 \prec|p| \prec \prec 1 \quad(\operatorname{resp} 0 \prec|q| \prec \prec 1)$ then

* $\quad \frac{b_{1}}{b_{2}} \approx \frac{a_{12}}{a_{22}} \approx \frac{a_{11}}{a_{21}} \approx \beta$
* the function $F=X_{1}-\beta X_{2}$ is a first integral of system (1)

* The singular place of the system (1) is defined by the equation $a_{11} X_{1}^{\left[\alpha_{1}\right]}+a_{12} X_{2}^{\left[\alpha_{2}\right]}+b_{1}=0$

iii. if $|p| \succ \succ 1$ (resp $|q| \succ \succ 1$ then

$\frac{q^{\left[\alpha_{2}\right]}}{p^{\left[\alpha_{1}\right]}}\left(\operatorname{resp} \frac{p^{\left[\alpha_{1}\right]}}{q^{\left[\alpha_{2}\right]}}\right)$ is appreciated and we have

$|q| \succ 1(\operatorname{resp}|p| \succ 1)$

Corollaire 1: a singular point of the system (1) taken in the region defined by $\left|X_{1}\right| \succ \succ 1\left(\operatorname{resp}\left|X_{2}\right| \succ \succ 1\right)$

, And in the region $A_{12}$ defined by the conditions

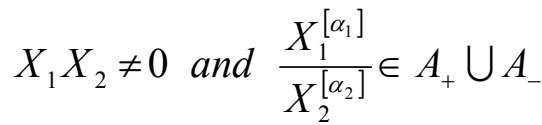

\section{Proof of proposition 3}

i. As $(\mathrm{p}, \mathrm{q})$ is not singular we have:

$\left\{\begin{array}{l}a_{11} P^{\left[\alpha_{1}\right]}+a_{12} q^{\left[\alpha_{2}\right]}+b_{1}=0 \\ a_{21} P^{\left[\alpha_{1}\right]}+a_{22} q^{\left[\alpha_{2}\right]}+b_{2}=0\end{array}\right.$

if $|p| \prec \prec 1 \quad(\operatorname{resp}|q| \prec \prec 1)$ then the real

$a_{12} p^{\left[\alpha_{1}\right]}$ and $a_{21} p^{\left[\alpha_{1}\right]}\left(\right.$ resp $a_{12} q^{\left[\alpha_{2}\right]}$ and $\left.a_{22} q^{\left[\alpha_{2}\right]}\right)$

are infinitely small.

where the following relations

$a_{12} q^{\left[\alpha_{2}\right]}+b_{1} \approx 0$ and $a_{22} q^{\left[\alpha_{2}\right]}+b_{2} \approx 0$

(resp $a_{12} p^{\left[\alpha_{1}\right]}+b_{1} \approx 0$ and $\left.a_{21} p^{\left[\alpha_{1}\right]}+b_{2} \approx 0\right)$.

As $a_{12}$ and $a_{22} \quad\left(\operatorname{resp} a_{11}\right.$ and $\left.a_{21}\right)$ are

appreciated we deduce the relations

$q^{\left[\alpha_{2}\right]} \approx-\frac{b_{1}}{a_{12}} \approx-\frac{b_{2}}{a_{22}}\left(\operatorname{resp} p^{\left[\alpha_{1}\right]} \approx-\frac{b_{1}}{a_{11}} \approx-\frac{b_{2}}{a_{21}}\right)$

but $\frac{b_{1}}{a_{12}}$ and $\frac{b_{2}}{a_{22}}$ (resp $\frac{b_{1}}{a_{11}}$ and $\left.\frac{b_{2}}{a_{21}}\right)$

are standard.

thus $\frac{b_{1}}{a_{12}}=\frac{b_{2}}{a_{22}} \quad\left(\operatorname{resp} \frac{b_{1}}{a_{22}}=\frac{b_{2}}{a_{21}}\right)$.

the relation $q^{\left[\alpha_{2}\right]} \approx-\frac{b_{1}}{a_{12}} \quad\left(\operatorname{resp} p^{\left[\alpha_{1}\right]} \approx-\frac{b_{1}}{a_{11}}\right)$

show

that

$|q| \approx 1($ resp $|p| \approx 1) \quad \sin c e-\frac{b_{1}}{a_{12}} \quad\left(\right.$ resp $\left.-\frac{b_{1}}{a_{11}}\right)$ is appreciated

The point ii) 
the obtained relation in (i) $\frac{b_{1}}{b_{2}}=\frac{a_{12}}{a_{22}}=\beta\left(\operatorname{resp} \frac{b_{1}}{b_{2}}=\frac{a_{11}}{a_{21}}=\beta\right) \quad$ implique the equality $a_{11} P^{\left[\alpha_{1}\right]}=-a_{12} q^{\left[\alpha_{2}\right]}-b_{1} \quad\left(\operatorname{resp} a_{22} q^{\left[\alpha_{2}\right]}=-a_{21} P^{\left[\alpha_{1}\right]}-b_{2}\right)$

As $p \neq 0(\operatorname{resp} q \neq 0)$ we obtain $a_{11}=\beta a\left(\operatorname{resp} \beta a_{22}=a_{12}\right)$ or as $\beta=\frac{a_{11}}{a_{21}}=\frac{a_{22}}{a_{21}}\left(\operatorname{resp} \frac{a_{11}}{a_{22}}=\frac{a_{22}}{a_{21}}\right)$ consequently $\frac{b_{1}}{b_{2}}=\frac{a_{22}}{a_{21}}=\frac{a_{22}}{a_{21}}=\beta$ hence the equality $\left(a_{11}, a_{12}, b_{1}\right)=\left(a_{21}, a_{22}, b_{2}\right)$ Which imply the relation $X_{1}^{\prime}-\beta X_{2}^{\prime}=0$ So the function $F=X_{1}-\beta X_{2}$ is a first integral of the system (1)

as $\left(a_{11}, a_{12}, b_{1}\right)=\beta\left(a_{21}, a_{22}, b_{2}\right)$ we see that $a_{11} X_{1}^{\left[\alpha_{1}\right]}+a_{12} X_{2}^{\left[\alpha_{2}\right]}+b_{1}=\beta\left(a_{21} X_{1}^{\left[\alpha_{1}\right]}+a_{22} X_{2}^{\left[\alpha_{2}\right]}+b_{2}\right)$ consequently the singular place of the system (1) is defined by the equation $a_{11} X_{1}^{\left[\alpha_{1}\right]}+a_{12} X_{2}^{\left[\alpha_{2}\right]}+b_{1}=0$

The point iii)

If $\quad|p| \succ \succ 1 \quad(\operatorname{resp}|q| \succ \succ 1) \quad$ the equality $a_{11} p_{1}^{\left[\alpha_{1}\right]}+a_{12} q_{2}^{\left[\alpha_{2}\right]}+b_{1}=0$ can also be written $a_{11}+a_{12} \frac{q^{\left[\alpha_{2}\right]}}{p^{\left[\alpha_{1}\right]}}+\frac{b_{1}}{p^{\left[\alpha_{1}\right]}}=0 \quad\left(\right.$ resp $\left.a_{12}+a_{11} \frac{p^{\left[\alpha_{2}\right]}}{q^{\left[\alpha_{1}\right]}}+\frac{b_{1}}{q^{\left[\alpha_{1}\right]}}=0\right)$ Show that $\frac{q^{\left[\alpha_{2}\right]}}{p^{\left[\alpha_{1}\right]}}\left(\operatorname{resp} \frac{p^{\left[\alpha_{1}\right]}}{q^{\left[\alpha_{2}\right]}}\right)$ can not be infinitely small or infinitely great because $a_{11}\left(\operatorname{resp} a_{12}\right)$ is standard nonnull and $\frac{b_{1}}{p^{\left[\alpha_{1}\right]}}\left(\operatorname{resp} \frac{b_{1}}{q^{\left[\alpha_{2}\right]}}\right)$ infinitely small .
Thus $\frac{q^{\left[\alpha_{2}\right]}}{p^{\left[\alpha_{1}\right]}}\left(\operatorname{resp} \frac{p^{\left[\alpha_{1}\right]}}{q^{\left[\alpha_{2}\right]}}\right)$ is appreciated as $p^{\left[\alpha_{1}\right]}\left(\operatorname{resp} q^{\left[\alpha_{2}\right]}\right)$ infinitely great, then it must be the same as $q^{\left[\alpha_{2}\right]}\left(\operatorname{resp} p^{\left[\alpha_{1}\right]}\right)$ such that the quotient is appreciated .

if $q^{\left[\alpha_{2}\right]}\left(\operatorname{resp} p^{\left[\alpha_{1}\right]}\right)$ is infinitely great, then $|q| \succ \succ 1 \quad(\operatorname{resp}|p| \succ \succ 1)$.

\section{REFERENCES}

1. Arnold, 1974. Equations Différentielle. Edition MIR. Moscou.

2. Bobo, S., 1988. Régionalisations et Van-der pol épaissi. Cahiers mathématiques d'Oran, fascicule $\mathrm{n}^{\circ} 2$.

3. Bobo, S., 1988. Méthode des régionalisations. Quelques applications I.R.M.A Strasbourg.

4. Callot, J.L., 1981. Bifurcation du portrait de phase pour des équations différentielles du second ordre, Thèse Strasbourg. 